\title{
The benefits of comparing solution methods in solving equations
}

\author{
Zuya Habila Elisha, PhD
}

\begin{abstract}
This study, which was experimental, investigated the benefits of comparing multiple solution methods in solving one and two-steps linear equations. The participants were 64 students from a private secondary school in the metropolitan area of Bauchi, Bauchi State of Nigeria. The students were randomly assigned to experimental and control groups. After pretest administration, there was an intervention for three days and on the fourth day the posttest was administered. The students learnt about solving equations either by comparing and contrasting solution methods or by reflecting on the same solution methods one at a time. The study revealed that students in the experimental group benefited more than those in the control group. At posttest, students in the experimental group had greater gains in procedural knowledge and flexibility knowledge than those in the control group. The findings of the study suggest that the method of comparing and contrasting solution methods can be an effective method in the mathematics classroom.

Keywords: Conceptual knowledge, Procedural knowledge, Mathematics education, Learning process, Flexibility knowledge
\end{abstract}

\section{Introduction}

There is a general consensus among mathematics educators that the teacher`s role in the mathematics classroom should be more of a facilitator, encouraging students to share and compare their own thinking and solution methods with other students (Hiebert \& Carpenter, 1992 [1]; NCTM, 1991 [2], 2000 [3]; Rittle-Johnson \& Star, 2007[4]). According to Rittle-Johnson and Star (2007) although there is abundance of descriptive research showing the value of this method, experimental studies that demonstrate its benefit are absent. They pointed out that they could not find studies that assessed the causal influence of comparing contrasting methods of student learning gains in mathematics.

Silver, Ghouseini, Gosen, Charalambous and Strawhun (2005[5]) said for the past two decades, a central tenet of reform pedagogy in mathematics has been that students benefit from comparing, reflecting on, and discussing multiple solution methods. Case studies of expert mathematics teachers emphasise the importance of students actively comparing solution methods (Ball, 1993 [6]; Fraivilling, Murphy \& Fuson, 1999 [7]; Huffred-Ackles, Fuson \& Shevin-Gamoran,2004[8]; Lampert, 1990[9]; Silver et al, 2005). Stigler and Heibert (1999[10]) maintained that teachers in high-performing countries such as Japan and Hong Kong often have students produce and discuss multiple solution methods. This emphasis on comparing and sharing solution methods was formalised in the NCTM standards (1989[11], 2000).Even though these and other studies provide evidence that sharing and comparing solution methods is an important feature of expert mathematics teaching, existing studies do not directly link this teaching practice to measured student outcome (Rittle-Johnson \& Star, 2007).

According to Rittle-Johnson and Star (2007) there is a robust literature in cognitive science that provides empirical support for the benefits of comparing contrasting examples for learning in other domains, mostly in laboratory settings (e.g. Namy \& Gentner,2002 [12]; Gentner, Leewenstein \& Thompson, 2003 [13]; Oakes \& Ribar, 2005[14] ). Gentner et al (2003) found that college students who were prompted to compare two business methods by reflecting on their similarities were much more likely to transfer the solution strategy to a new case than were the students who read and reflected on the cases independently. Thus identifying similarities and differences in multiple examples may be a critical and fundamental pathway to flexible, transferable knowledge. Such a research has not been done with mathematics students or in classroom settings except the one by Rittle-Johnson \& Star (2007).

This study tried to replicate the study conducted by Rittle-Johnson and Star (2007) with little modifications, especially with respect to participants. The study focused on procedural knowledge, flexibility and conceptual knowledge as these are the three critical components of mathematics competence. Rittle-Johnson, Siegler and Alibali (2001[15]) defined procedural knowledge as the ability to execute action sequences to solve problems, including the ability to adapt known procedures to novel problems. Kilpatrick, 
Swafford and Findel $(2001[16])$ and Star $(2005[17])$ both defined procedural flexibility as the ability to solve problems in multiple ways, and when to use them. Kilpatrick et al (2001) defined conceptual knowledge as 'an integrated and functional grasp of mathematical ideas'. They pointed out that this knowledge is flexible and not tied to specific problem type and is therefore generalisable.

The study investigated the effectiveness of comparing multiple solution methods for learning algebra.

Algebra is an important component of mathematics. According to Kieran (1992[18]), Algebra has represented students' first sustained exposure to the abstraction and symbolism that make mathematics powerful. Linear equation solving one of the components of Algebra is considered a basic skill by many in mathematics education. However, students' difficulties in algebra have been well documented in national and international assessments (Rittle-Johnson \& Star, 2007). Current mathematics curricula typically do not focus sufficiently on flexible and meaningful solving of equations (Kieran, 1992).

\section{Statement Of The Problem}

Though there is robust literature in cognitive science that provides empirical support for the benefits of comparing contrasting examples for learning in other domains, there is the absence of this research in mathematics (except the one by Rittle-Johnson \& Star, 2007). This study was partially a replica of the work of Rittle-Johnson and Star (2007) using a design to investigate whether comparing solution methods promoted greater learning in mathematics than studying methods one at a time.

\section{Purpose Of The Study}

The main purpose of the study was to investigate the benefits of comparing solution methods. Specifically, the study aimed at determining:

1. whether comparing multiple solution methods would promote greater learning in mathematics than studying methods one at a time.

2. whether students would show greater improvements from pretest to posttest on three outcome measuresprocedural knowledge, flexibility and conceptual knowledge.

\section{Research Questions}

The following research questions were formulated to guide the study:

1. Would students who learn mathematics by comparing solution methods show greater improvements from pretest to posttest on procedural knowledge, flexibility knowledge and conceptual knowledge?

2. Are students who learn by comparing solution methods more efficient in solving mathematics problems than those who learn by studying one method at a time?

The following hypothesis was tested at 0.05 :

\section{Hypothesis}

HO1: There is no significant difference between the mean scores of the students who studied by comparing solution methods and those who studied one method at a time.

\section{VI.I Design of the Study}

\section{Methodology}

The pretest-intervention-posttest design was employed in this study. Students were randomly selected and paired with one another in their classes, and the pairs of students were randomly assigned to experimental and control groups.

\section{VI.II Participants}

The participants for the study were senior secondary I students in private school in Bauchi metropolitan area. The students were 64 in number from two classes ( 36 boys and 28 girls) with mean age 15 years. The main text used is the General Mathematics for Senior Secondary, and the students have learnt about simplifying algebraic expressions and solving one step and simple two step equations. The main strategy used, according to the mathematics teacher, is the conventional method. However, he said sometimes other solution methods are employed.

\section{VI.III Instrument}

The same instrument was used for both pretest and posttest. The instrument which was adopted from the work of Rittle-Johnson and Star (2007) was designed to measure procedural, flexibility and conceptual knowledge. The procedural knowledge items were 8 in number; 4 familiar and 4 novel equations. The flexibility items were 6 in number to tap three components of flexibility- ability to generate, recognize and evaluate 
multiple solution methods for the same problem. The conceptual knowledge items were also 6 in number, designed to measure the student's verbal and nonverbal knowledge of Algebra concepts.

\section{VI.IV Intervention package}

The intervention package was mainly the one developed by Rittle-Johnson and Star (2007). The package was made up of 4 types of equations- divide composite, combine composite, subtract composite and conventional. Examples are shown in TABLE 1.

Table1 Four Types of Equations in the Intervention Package

\begin{tabular}{clc}
\hline$a(x+b)=c$ & e.g. $5(x+1)=10$ & Divide composite \\
$a(x+b)+d(x+b)=c$ & e.g. $3(x+2)+2(x+2)=15$ & Combine composite \\
$a(x+b)=d(x+b)+c$ & e.g. $6(x+1)=4(x+1)+8$ & Subtract composite \\
$a(x+b)+d x+e=f(g x+h)+i x+c$ & e.g. $2(x+1)+3 x+5=4(2 x-1)+2 x+6 \quad$ Conventional
\end{tabular}

For the experimental group there were 12 equations with each equation solved in two different ways, and presented side by side on the same page. Steps taken to solve the equations are shown and labeled as either distribute, combine, add/subtract on both sides or multiply/divide on both sides. On some examples students were required to label some of the steps, and this was to encourage active participation. For each pair of worked example, two questions were asked to prompt students to compare and contrast the two methods. A sample page from the packet is shown in Fig. 1.

For the control group, there were 24 worked examples- the 12 equations from the experimental group and an isomorphic equation for each that was identical in form and varied only in the particular numbers. In this group, each worked example was presented on a separate page, but same solution methods were used in solving the equations. Just as in the experimental group, steps were labeled and students were required to supply some. A question was asked for each of the 24 worked examples prompting the students to reflect on that solution. A pair of sample pages from this packet is shown in Fig. 2.

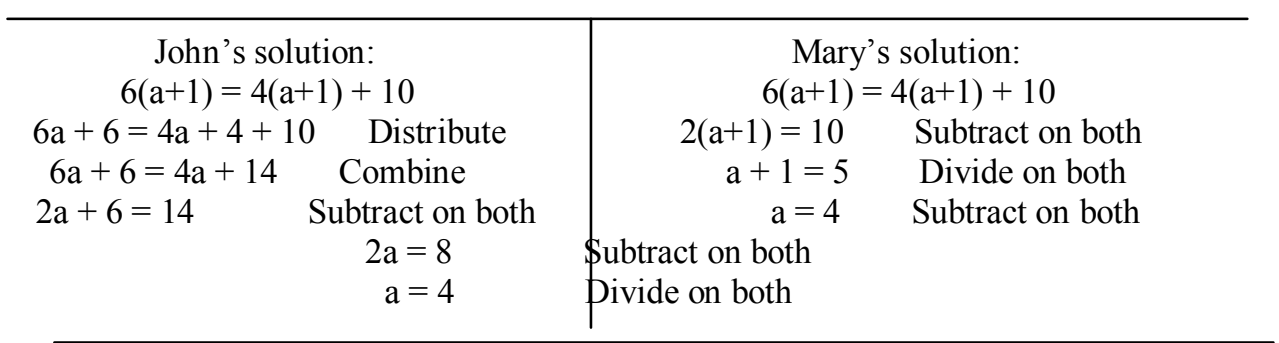

1. John and Mary solved the problem differently, but they got the same answer. Why?

2. Why might you choose to use Mary's way?

Figure 1: Sample page from the intervention packet for experimental group

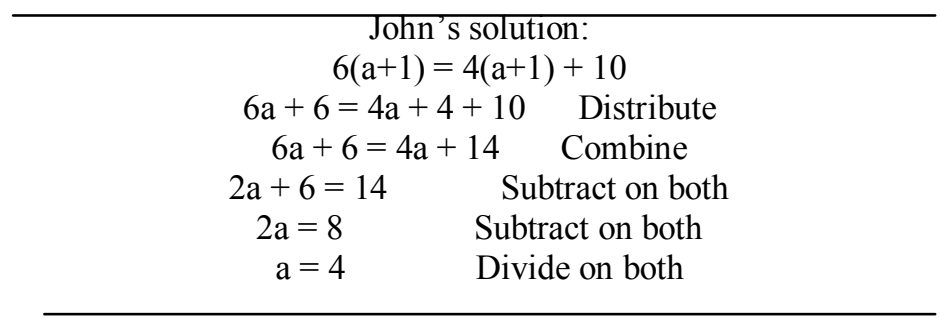

1. Would you choose to use John's way to solve problems like this? Why or why not?

\begin{tabular}{cc} 
Mary's solution: \\
$12(a+1)=8(a+1)+12$ \\
$4(a+1)=12$ & Subtract on both \\
$a+1=3$ & Divide on both \\
$a=2$ & Subtract on both \\
\hline
\end{tabular}

1. Check Mary's solution by substituting her answer into the equation. 
Did Mary get the correct answer?

Figure 2: A pair of sample pages from the intervention packet for control group

\section{VI.V Procedure}

The pretest was administered on the first day, and it lasted for 40 minutes, including the 16 minutes for solving the 8 procedural knowledge items. To encourage students use efficient solution methods on part one of the instruments, time limit was placed on the procedural knowledge items.

On Day two, the intervention package was introduced. Students sat in pairs with their partners, and studied the worked examples covering the first two equation types in TABLE 1 . When studying the worked examples the students were required to describe each solution to their partners and answer the accompanying questions first verbally and then in writing. Each pair had a single worked example packet and was encouraged to take turns writing their responses.

On the third day, the third and fourth equation types as shown in TABLE 1 were covered. Before students started working on the worked examples, it was stressed to them that there was more than one way of solving the problem. Students sat with their partners and worked on the second study packet of worked examples. On day four, students were given 40 minutes to complete the posttest, which was identical to the pretest in content and administration.

\section{VI.VIScoring}

The procedural knowledge items were scored 1point for each correct answer. For the two generating multiple methods of the flexibility items, 1 point if two different ways were correct solutions. For the two recognizing multiple methods of the flexibility items, 1 point for each correct choice. For evaluating nonconventional methods, 1 point for correctly identifying step, 2 points for choice (a) and 1 point for choice (b). And for explaining or justifying reason (say quicker/easier) 3 points; 2 points for quicker/easier; 1 point if do not reject, but prefer alternative. For the conceptual knowledge items, 1 point for correct choice of the solution, and 2 points for justifying reason.

\section{Results}

The mean scores and standard deviations of the students in the three measures are presented in TABLE 2. It can be noticed from the table that students have had some knowledge in algebra before the intervention. It was noted earlier on that students have had lessons on solving one-step and two-step equations. At pretest, there was no significant difference between the mean scores of the experimental and control groups in the three measures- procedural knowledge, flexibility knowledge and conceptual knowledge- $\mathrm{F}(1,62)=2.47$, 1.83 and 1.57 respectively, with $\mathrm{p}=0.17$.

Table 2 Performance of students by group

\begin{tabular}{|c|c|c|c|c|c|c|}
\hline \multicolumn{2}{|c|}{ Pretest } & \multicolumn{2}{|c|}{ Posttest } & \multicolumn{2}{|c|}{ Gain scores } & \multirow[b]{2}{*}{$\mathrm{SD}$} \\
\hline Group & M & SD & M & SD & $\mathrm{M}$ & \\
\hline Procedural & 13.4 & 6.1 & 41.6 & 11.3 & 28.2 & 9.5 \\
\hline Flexibility & 27.5 & 8.7 & 60.2 & 12.1 & 32.7 & 10.7 \\
\hline Conceptual & 38.2 & 10.2 & 54.7 & 9.1 & 16.5 & 7.2 \\
\hline \multicolumn{7}{|c|}{ Control } \\
\hline Procedural & 17.6 & 7.4 & 37.2 & 8.9 & 19.6 & 9.1 \\
\hline Flexibility & 20.7 & 9.3 & 44.3 & 10.4 & 23.6 & 9.8 \\
\hline Conceptual & 39.4 & 7.6 & 58.1 & 11.6 & 18.7 & 10.1 \\
\hline
\end{tabular}

At posttest, there were significant differences between the mean scores of the students in the experimental and control groups in procedural knowledge and flexibility knowledge $F(1,62)=2.51$ and 2.26 respectively, with $\mathrm{p}=0.001$. Students in experimental and control groups did not differ in conceptual knowledge at posttest, $\mathrm{F}(1,62)=1.07, \mathrm{p}=0.08$.

Students in the experimental condition were expected to be more flexible and accurate in solving problems by using the demonstrated short cuts at posttest rather than the conventional method. Frequency count of using the solution methods available indicated that the students in the experimental group used the demonstrated short cut method more than those in the control group at posttest (TABLE 3 ). The flexibility items comprised of items on recognize, generate and evaluate. The experimental group students were able to evaluate methods at posttest, as they were presented with multiple solutions to the same problem side by side on the same 
page during the intervention. Though students in the experimental and control groups did not differ in conceptual knowledge at posttest, there were improvements in conceptual knowledge from pretest to posttest across groups (TABLE 2).

On the gains from pretest to posttest, it was anticipated that students in the experimental group would make greater gains. This is evident from TABLE 2. A closer look at the gains from pretest to posttest of the two groups indicated that experimental group had greater gains in procedural knowledge and flexibility knowledge, except in conceptual knowledge.

Table 3 Proportion of Solution Methods used by Group

\begin{tabular}{lcccc}
\hline \multirow{1}{*}{ Solution method } & Pretest & \multicolumn{2}{c}{ Posttest } \\
Conventional & 0.54 & 0.56 & 0.65 & 0.71 \\
\hline Demonstrated shortcut & 0.00 & 0.00 & 0.21 & 0.10 \\
Other & 0.35 & 0.34 & 0.11 & 0.14 \\
Blank & 0.11 & 0.10 & 0.03 & 0.05 \\
& & & & \\
\hline
\end{tabular}

\section{Discussion}

The study revealed that comparing multiple solution methods led to improvements in procedural knowledge and flexibility knowledge in solving equations, as against learning multiple methods one at a time. This finding agrees with the findings by Rittle-Johnson and Star (2007). The findings of the study also agree with prior cognitive science research on comparison as a basic learning methodology (Gentner, Loewenstein \& Thompson, 2003; Namy \& Gentner, 2002). It is also an indicator that this methodology can be used or employed to teach mathematics, especially algebra.

Comparing contrasting solution methods, the study revealed, helps students to differentiate essential features of a problem, such as becoming aware of shortcuts and efficiency of methods (Schwartz \& Bransford, 1998 [19]). This methodology seems to encourage students consider multiple methods in solving problems in general.

It was expected that students' greater improvements in procedural knowledge would be accompanied by corresponding improvements in conceptual knowledge. The study showed significant difference across groups with respect to procedural knowledge in posttest. But there was no significant difference across the groups with respect to conceptual knowledge in posttest. However, students in both groups made appreciable improvements on measure of conceptual knowledge. This is in line with findings by Rittle-Johnson and Star (2007). The possible reasons for the no difference across the groups with respect to conceptual knowledge could be those noted by Rittle-Johnson and Star (2007), as the probing questions on the concepts, the time of the intervention too short, and covering wider variety of problems and directing the conceptual knowledge measure to assess variables.

\section{Implications For Education}

This study provides experimental evidence supporting the benefits of comparing solution methods in mathematics, besides the one conducted by Rittle-Johnson and Star (2007). The findings of the study suggest the need to provide to-be-compared solution methods with the solution steps aligned (Richland, Zur \& Hulyoak, 2007 [20]; Rittle-Johnson \& Star, 2007), as this would support comparison in the class room. Some Mathematics educators have pointed out that opportunities for identifying similarities and differences in methods should be encouraged (e.g. Fraivillig, Murphy \& Fuson, 1999; Huffred-Ackles, Fuson \& SherinGamoran, 2004; Silver, Ghouseini, Gosen, Charalambous \& Strawhun, 2005) as this leads to transfer of knowledge.

In this study, students were prompted to consider the efficiency of methods, and this was shown to be effective method of problem solving, especially in algebra. Contrasting solution methods with clear comparison prompts might support effective instruction in the class room.

\section{Conclusion}

It is evident from the study that comparing multiple solution methods is an important learning process, especially in solving simple equations. In particular, this learning strategy facilitates procedural knowledge and flexibility knowledge. Therefore, engaging in active sharing- and-comparing solution methods in an important reform activity in mathematics. 


\section{References}

[1]. J. Heibert \& T. Carpenter, Learning and teaching with understanding. In D. Grouws (Ed.). Handbook of research on mathematics teaching and learning. (New York: Simon \& Schuster Macmillan, 1992), 65-97

[2]. National Council of Teachers of Mathematics.Professional standards for teaching mathematics ( Reston, VA: Author,1991)

[3]. National Council of Teachers of Mathematics.. Principles and standards for school mathematics (Reston, VA: Author, 2000)

[4]. B. Rittle-Johnson, and J. Star, (2007). Does comparing solution methods facilitate conceptual and procedural knowledge? An experimental study on learning to solve equations. Journal of Educational Psychology, 99, 3, 2007, 561-574

[5]. E. A., Silver, H., Ghousseini, D., Gosen, C., Charalambous, and B. Strawhun, Moving from rhetoric to praxis: Issues faced by teachers in having students consider multiple solutions for problems in the mathematics classroom. Journal of mathematical behavior, 24, 2005, 287-301.

[6]. D. L. Ball, With an eye on the mathematical horizon: Dilemmas of teaching elementary school mathematics. The elementary School Journal, 93, 1993, 373-397.

[7]. J. L., Fraivilling, L. A Murphy and K. Fuson, Advancing children's mathematical thinking in everyday mathematics classrooms. Journal for Research in Mathematics Education, 30, 1999, 148-170.

[8]. K., Huffred-Ackles, K., Fuson and M. Sharin Gamoran, Describing levels and components of a math-talk learning community. Journal for Research in Mathematics Education, 35, 2004, 81-116.

[9]. M . Lamper, When the problem is not the question and the solution is not the answer: Mathematical knowing and teaching, American educational research journal, 27, 1990, 29-63.

[10]. J. W., Stigler, and J. Hiebert, (1999). The teaching gap: Best ideas from the world's teachers for improving education in the classroom ( New York: Free Press, 1999)

[11]. National Council of Teachers of Mathematics, Curriculum and evaluation standards for school Mathematics ( Reston, VA: Author, 1989)

[12]. L. L. Namy and D. Gentner, Making a silk purse out of two sow's ears: Young children use of comparison in category learning, Journal of experimental psychology: General, 131, 2002, 5-15.

[13]. D., Gentner, J., Loewenstein, and L. Thompson,Learning and transfer: A general rule for analogical Encoding, Journal of Educational Psychology, 95, 2003, 393-405.

[14]. M., Oakes and R. J. Ribar, (2005). A comparison of infants' categorization in paired and successive presentation familiarization tasks, Infancy, 7, 2005,85-98.

[15]. B., Rittle-Johnson R. S. Siegler, and M. W. Alibali, (2001). Developing conceptual understanding and procedural skill in mathematics: An iterative process. Journal of Educational Psychology, 93, 2001,346- 362.

[16]. J., Kilpatrick, J. O., Swafford, and B. Findell, (Eds.) Adding it up: Helping children learn mathematics (Washington, DC: National Academy Press, 2001)

[17]. J. R. Star ,Reconceptualising procedural knowledge, Journal for research in mathematics education, 36, 2005,404 - 411.

[18]. C. Kieran, The learning and teaching of school algebra. In D. Grouws (Ed.). Handbook of research on mathematics teaching and learning ( New York: Simon Schuster Macmillan, 1992). 390-419

[19]. D. L., Schwarzt, and J. D. Bransford, A time for telling. Cognition and instruction, 16, 1998, 475-522

[20]. L. E., Richland, O. Zur, and K. J. Holyoak, Cognitive supports for analogies in the mathematics classroom. Science, 316 , 2005, 1128-1129. 